\title{
Effect of ischaemia on peripheral nerve function in patients with chronic renal failure undergoing dialysis treatment
}

\author{
P. CASTAIGNE, H.-P. CATHALA, L. BEAUSSART-BOUlengé, \\ AND M. PETROVER \\ From the Laboratoire d'EMG, Clinique des Maladies du Système Nerveux, \\ Hôpital de la Saltpêtrière, Paris, France
}

SUMMARY During 30 minutes of maintained ischaemia of the upper limb, the nerve action potential (NAP) persists in some uraemic patients until the end of the test, and in all patients significantly longer than in normal subjects. Such behaviour is similar to that seen in diabetic patients and unlike that seen in people receiving high doses of insulin and glucose perfusion. Renal dialysis increases this tendency, while macromolecular perfusion after dialysis tends to correct it.

In a previous paper (Castaigne, Cathala, Dry, and Mastropaolo, 1965), we described the effects in normal man of a 30 minute ischaemic test upon latency and amplitude of the nerve action potential (NAP), registered from the ulnar nerve at the elbow after electrical stimulation at the wrist. Ischaemia is produced by a sphygmomanometer cuff applied on the upper arm and inflated to a slightly higher level than the systolic blood pressure for a 30 minute period. Latency of the evoked response increases coincidentally with a reduction in amplitude until the NAP disappears, most often between the 20th and 25th minutes of ischaemia (Fig. 1). Disappearance of the NAP is not due to lowering of local temperature; a thermocouple placed near the ischaemic nerve trunk shows an average reduction of only $2 \cdot 5^{\circ} \mathrm{C}$, which is not sufficient to explain the decrease in conduction velocity and the disappearance of the NAP. Furthermore, reduction in NAP amplitude begins to appear after three to five minutes of ischaemia, and reappears 15 to 30 seconds after release of the cuff. Nor is the phenomenon induced by direct pressure on the nerve trunk, since there is no difference in the course of events when two cuffs are successively inflated on different parts of the arm to maintain ischaemia while local effects of pressure are corrected (Cathalo and Scherrer, 1963).
This same method has disclosed in diabetic patients a sort of 'resistance' to ischaemia (Castaigne, Cathala, Mastropaolo, Dry, and Gras, 1966a): latency of the nerve response develops more slowly and the NAP does not disappear during 30 minutes of ischaemia (Fig. 2). These results are in agreement with those reported by Steiness (1963), Gregersen (1964), and Christensen and Ørskov (1969), who described a marked prolongation of vibratory perception during ischaemia in patients with diabetes mellitus or with chronic renal failure. Using our own ischaemic test, we have found increased 'resistance' in uraemic patients investigated before renal dialysis (Cathala, Beaussart-Boulengé, Meyrier, and Damame, 1971) (Fig. 3), and decreased 'resistance' in people having massive insulin therapy and glucoseperfusion (Fig. 4). In the present work we wish to emphasize the phenomenon of ischaemic 'resistance' in uraemic patients in regard to different modes of renal dialysis.

\section{METHOD}

We investigated 20 patients with chronic renal failure: 10 women from 22 to 52 years of age, and 10 


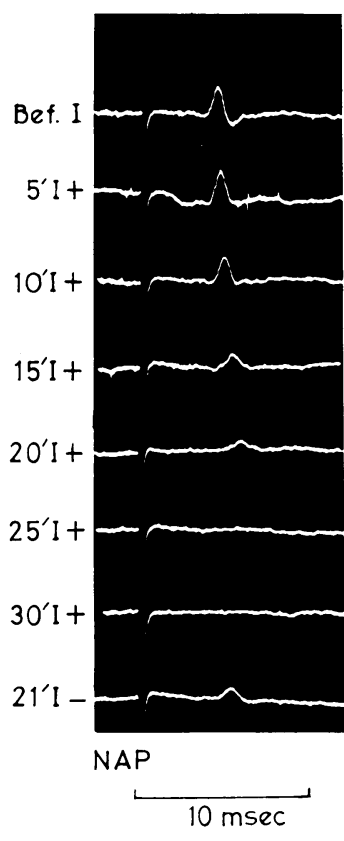

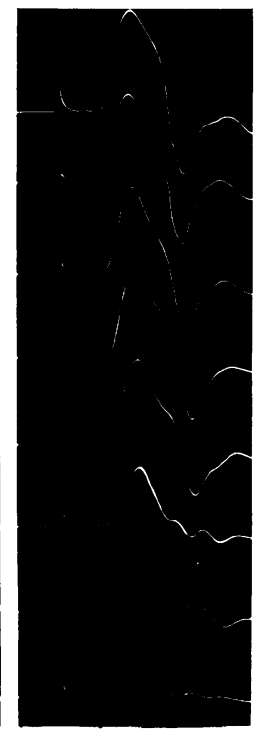

Short distance muscle action potential

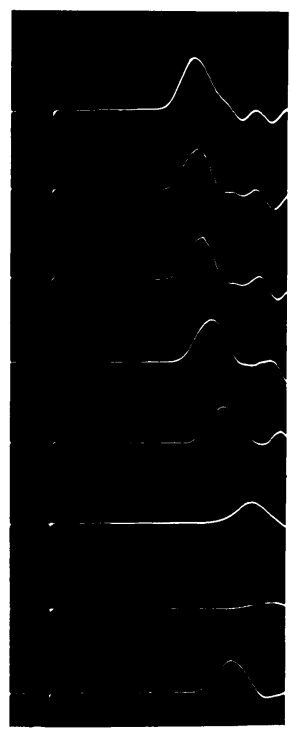

Long distance 10 msec

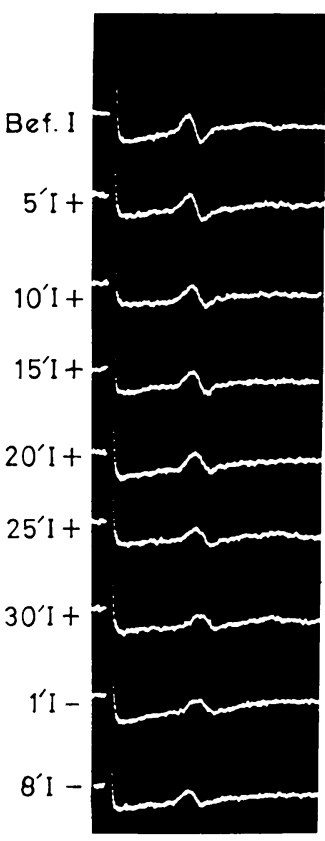

NAP

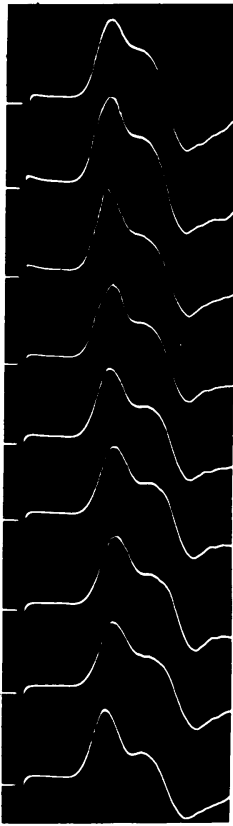

Short distance
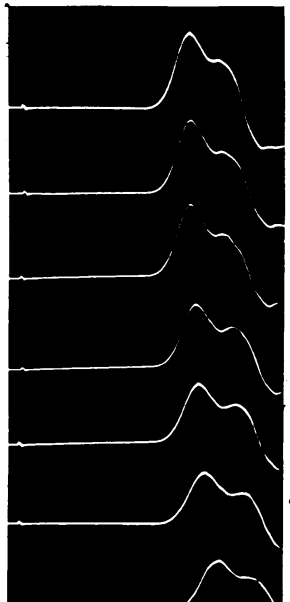
diabetic neuropathy showing persistence of NAP after 30 minutes of ischaemia.

FIG. 1. Latencies of nerve action potential (NAP) of ulnar nerve at elbow evoked by stimuli at the wrist and muscle action potential from adductor pollicis brevis muscle evoked from wrist ('short distance') and elbow ('long distance'). Normal subject. The NAP disappears after 20 minutes of ischaemia and muscle action potential decreases when stimulated at the elbow (distal to the cuff) but not when stimulated at the wrist. 
men from 24 to 58 years of age. Diagnoses were as follows; the numbers indicating cases:

Glomerulonephritis after acute nephritis . 8

Interstitial nephropathy . . . 2

Nephroangiosclerosis . . . . . 2

Post-partum nephritis . . . . . 1

Acute nephrotic syndrome . . . . 1

Polycystic disease of kidneys . . . 1

Alpert's syndrome . . . . . 1

Renal failure without known aetiology . 4

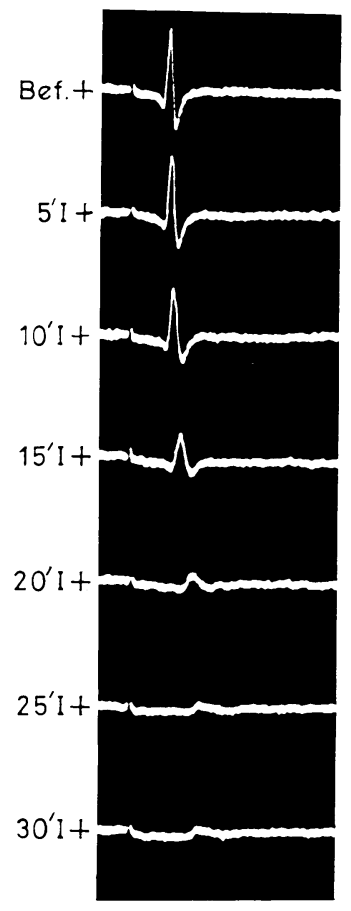

Release of Ischaemia

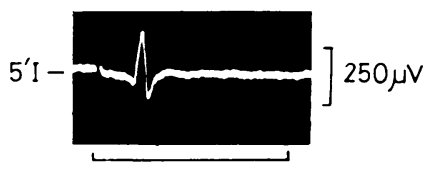

$10 \mathrm{msec}$

FIG. 3. Effect of ischaemia for 30 minutes on ulnar nerce $\mathrm{NAP}$ in a patient with chronic renal failure before dialysis. Relatice persistence of NAP.

Two patients had bilateral nephrectomy. Only one presented clinical symptoms of polyneuritis. All were under treatment with two to three dialysis sessions a week and rigidly controlled diet to avoid weight increase of more than $1 \mathrm{~kg}$ between dialyses.

All of these patients had their first electrical examination the day before dialysis, and their second examination the day after dialysis which was conducted in such a way as to obtain relative hypovolaemia with a weight loss of about $2 \mathrm{~kg}$. All patients were kept in a fasting state after dialysis until the conclusion of these examinations. Immediately afterwards we tried to correct hypovolaemia by a macromolecular perfusion (with Rheomacrodex), and then patients were examined a third time. Severe cramps in three patients prevented us from completing their last examination. Eighteen of our patients were also given an ischaemic test after dialysis, but without induction of hypovolaemia and consequently little change in weight.

Each electrical examination included: (1) Measurement of the conduction velocity of the anterior tibial nerve (motor fibres) and ulnar nerve (motor and sensory fibres and NAP); (2) EMG of tibialis anterior muscle and of 1st dorsal interosseous muscle; (3) Ischaemic test of 30 minutes on the upper limb.

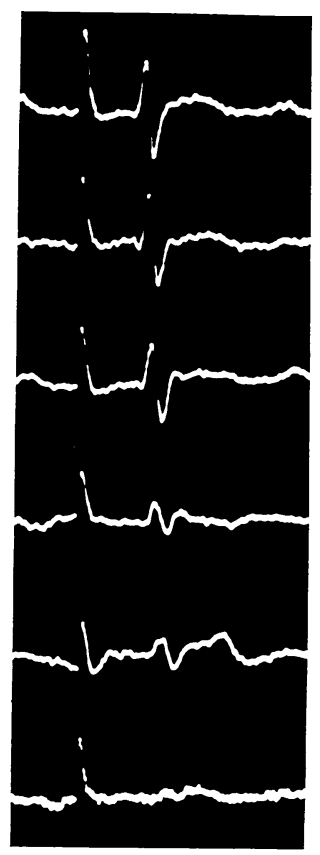

a

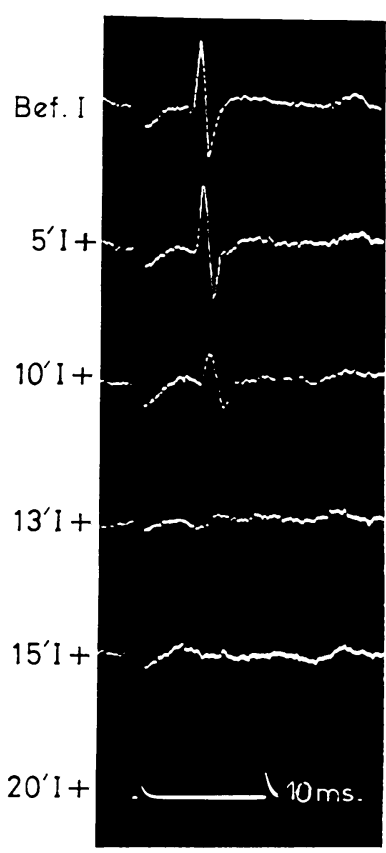

b
FIG. 4. Resistance of NAP to ischaemia after insulin 200 i.u. (blood glucose $31 \mathrm{mg} / 100 \mathrm{ml}$.). (b) Normal persistence of NAP to same duration of ischaemia when blood sugar level restored by glucose perfusion. 
TABLE 1

AVERAGED CONDUCTION VELOCITIES OF ULNAR NERVE

( 20 SUBJECTS)

\begin{tabular}{|c|c|c|c|}
\hline & $\begin{array}{l}\text { Motor fibres } \\
\text { (elbow to wrist) } \\
\quad(\mathrm{m} / \mathrm{sec})\end{array}$ & $\begin{array}{l}\text { Sensory fibres } \\
\text { (finger to wrist) } \\
\quad(\mathrm{m} / \mathrm{sec})\end{array}$ & $\begin{array}{l}\text { Nerve action potential } \\
\text { (wrist to elbow) } \\
(\mathrm{m} / \mathrm{sec})\end{array}$ \\
\hline $\begin{array}{l}\text { Before dialysis } \\
\text { After dialysis with hypovolaemia } \\
\text { After correction by Rheomacrodex } \\
\text { After dialysis without hypovolaemia }\end{array}$ & $\begin{array}{l}49 \cdot 80 \pm 5 \cdot 06 \\
48 \cdot 41 \pm 10 \cdot 94 \\
50 \cdot 62 \pm 7 \cdot 80 \\
50 \cdot 82 \pm 5 \cdot 72\end{array}$ & $\begin{array}{l}44 \cdot 48 \pm 4 \cdot 78 \\
41 \cdot 67 \pm 5 \cdot 10 \\
42 \cdot 08 \pm 5 \cdot 59 \\
46 \cdot 28 \pm 4 \cdot 34\end{array}$ & $\begin{array}{l}51 \cdot 39 \pm 4 \cdot 56 \\
50 \cdot 35 \pm 4 \cdot 56 \\
49 \cdot 82 \pm 5 \cdot 49 \\
52 \cdot 21 \pm 4 \cdot 60\end{array}$ \\
\hline
\end{tabular}

\section{RESULTS}

EMG AND CONDUCTION VELOCITIES We found a 'neurogenic' EMG in the tibialis anterior muscle in only one patient and we noted no characteristic pattern after either of the two different modes of dialysis, nor after Rheomacrodex perfusion.

Anterior tibial nerve conduction velocities were normal in 17 patients; one case showed no muscle response and two cases showed reduced velocity. Ulnar nerve conduction velocities were all within normal limits.

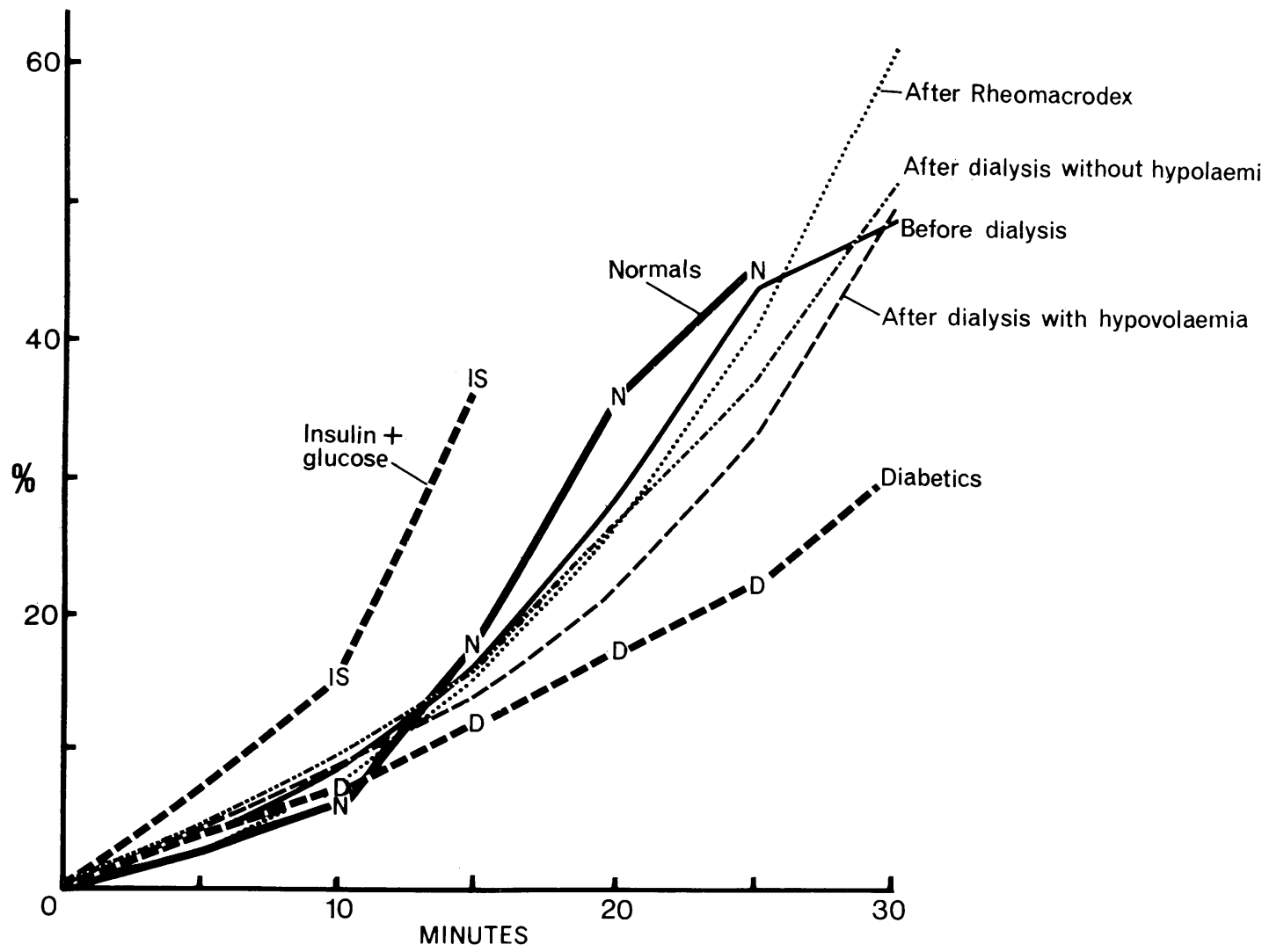

FIG. 5. Chronic renal failure. Increasing latency of NAP during ischaemia expressed as $\%$ of pre-ischaemia latency: before dialysis; after dialysis with hypovolaemia; after perfusion with Rheomacrodex; after dialysis without hypovolaemia. 
TABLE 2

DISAPPEARANCE TIME OF NERVE ACTION POTENTIAL

\begin{tabular}{|c|c|c|c|c|c|c|c|c|c|}
\hline & \multicolumn{2}{|c|}{$\begin{array}{l}\text { Before } \\
20 \text { th } \min \end{array}$} & \multicolumn{2}{|c|}{$\begin{array}{c}\text { Between } \\
\text { 21st and 25th min }\end{array}$} & \multicolumn{2}{|c|}{$\begin{array}{c}\text { Between } \\
26 \text { th and 30th min }\end{array}$} & \multicolumn{2}{|c|}{$\begin{array}{c}\text { No } \\
\text { disappearance }\end{array}$} & \multirow[t]{2}{*}{$\begin{array}{l}\text { Total } \\
\text { (no.) }\end{array}$} \\
\hline & (no.) & $(\%)$ & (no.) & $(\%)$ & (no.) & $(\%)$ & (no.) & $(\%)$ & \\
\hline Normals & 5 & 18 & 21 & 75 & 2 & 7 & 0 & 0 & 28 \\
\hline Before dialysis & 0 & 0 & 4 & 20 & 7 & 35 & 9 & 45 & 20 \\
\hline After dialysis with hypovolaemia & 0 & 0 & 0 & 0 & 3 & 15 & 17 & 85 & 20 \\
\hline After correction by macromolecular & & & & & & & & & \\
\hline perfusion & 0 & 0 & 7 & $41 \cdot 2$ & 6 & $35 \cdot 3$ & 4 & $23 \cdot 5$ & 17 \\
\hline After dialysis without hypovolaemia & 0 & 0 & 3 & $13 \cdot 6$ & 4 & $22 \cdot 2$ & 11 & $61 \cdot 2$ & 18 \\
\hline Diabetics & 0 & 0 & 2 & $4 \cdot 3$ & 1 & $2 \cdot 2$ & 43 & $93 \cdot 5$ & 46 \\
\hline $\begin{array}{l}\text { Insulin treatment }+ \text { glucose } \\
\text { perfusion }\end{array}$ & 10 & 76 & 3 & 14 & 0 & 0 & 0 & 0 & 13 \\
\hline
\end{tabular}

The two different modes of dialysis appear to have no effect on the mean value of nerve conduction velocity (Table 1).

LENGTHENING OF NAP LATENCY We estimated lengthening of NAP latency as a percentage of the initial value obtained before the beginning of the ischaemic test, in order to obviate the influence of different arm size in patients. The curve of mean percentage values plotted against duration of ischaemia showed a slope very similar to that obtained for normal patients; in contrast, the slope rose significantly more slowly in diabetic patients, and more rapidly for psychotic patients treated with large doses of insulin followed by glucose perfusion (Fig. 5).

In patients with chronic renal failure there was no significant difference in the rate of increasing latency between any of the four different situations tested. Although large individual differences occurred, nothing systematic was observed in curves of mean values (Fig. 5).

NAP-DISAPPEARANCE TIME (Table 2) This parameter gave us the clearest results. In normal people NAP usually vanishes between the 21 st and 25 th minute of ischaemia, infrequently before, rarely later; and never after 30 minutes of ischaemia. In diabetics, as a general rule, the NAP is still clearly perceptible after 30 minutes of ischaemia whatever the blood glucose level, the treatment or the type of syndrome, including even the existence of associated neuropathy (Castaigne et al., 1965; Castaigne and Cathala, 1967) (see also Fig. 2). In contrast, in the majority of people receiving large doses of insulin and glucose, the NAP disappears before the 20th minute of ischaemia, sometimes before the 15th (Cathala et al., 1970) (see also Fig. 4).

In our patients with chronic renal failure we have found several remarkable things regarding the disappearance time of the NAP; when the data are distributed among successive time periods, the following statistical analysis can be made (Table 2):

1. NAP disappears sooner in normal subjects than in undialysed uraemic patients $(\mathrm{P}<0.01)$ and sooner in uraemic patients than in diabetics $(\mathrm{P}<0.05)$.

2. NAP disappears later in dialysed uraemic patients, no matter what method of dialysis was used, than in the same patients before dialysis $(\mathrm{P}<0.05)$.

3. In the subgroup of uraemic patients undergoing hypovolaemic renal dialysis followed by macromolecular perfusion, the NAP disappears sooner than in the same patients before perfusion $(P<0.01)$; the distribution of the NAP disappearance times approaches that seen in normal people.

3. Finally, there was no correlation between ischaemic patterns and weight variations induced by dialysis or perfusion.

To summarize our results, uraemic patients show a clearly greater 'resistance' to ischaemia than normal people, but less than diabetics. Dialysis with or without hypovolaemia seems to have the same effect on nerve conduction in exaggerating ischaemic 'resistance'. Macro- 
molecular perfusion to reverse hypovolaemia decreases the 'resistance' to near normal limits. The rate of increasing latency of the evoked NAP during ischaemia remains close to normal in all uraemic patients, no matter what the circumstances of treatment, but latency increases for longer while NAP does not disappear so quickly.

\section{DISCUSSION}

Our results corroborate those of Christensen and Orsk ov (1969): patients with chronic renal failure seem to present a curious 'resistance' to ischaemia similar to that described in diabetics (Steiness, 1963; Castaigne et al., 1966b; Castaigne and Cathala, 1967). It should be emphasized that the effects of ischaemia are not identical in the two groups.

Seneviratne and Peiris (1970) have reported a similar condition in patients with chronic liver disease. Shahani and Russell (1969) suggested that patients with peripheral neuropathy show the same phenomenon for sensory fibres, but their three patients had no sensory defect, and pyramidal symptoms were associated with peripheral signs. It seems that all three of their cases probably had amyotrophic lateral sclerosis.
Furthermore, they based their opinion on the fact that, in contrast with normal, the H-reflex disappeared during ischaemia, while the direct response persisted, and they thus chose to study muscle responses. However, we have shown (Castaigne et al., 1966a; Castaigne and Cathala. 1967) that muscle responses seem to be much less influenced by ischaemia than nerve responses. When a muscle response vanishes during ischaemia, it is almost always when the nerve impulse traverses a relatively long distance under ischaemic conditions. For example, the response of the adductor pollicis brevis muscle remains normal after stimulation at the wrist, whereas it disappears after stimulation at the elbow (Fig. 1). This could be due to the disclosure under ischaemia of a tendency to decremental conduction in long human nerve trunks, and could explain the lability of the $\mathrm{H}$-response under ischaemia. In a personal series of 12 normal people, the muscle response to a stimulus at a long distance disappeared seven times under ischaemia and remained normal five times. It is therefore probably not possible to base anyo conclusion on the three patients of Shahani anc Russell. Furthermore, we studied 13 non $\frac{\mathbb{8}}{2}$ diabetic patients with peripheral neuropathie 0

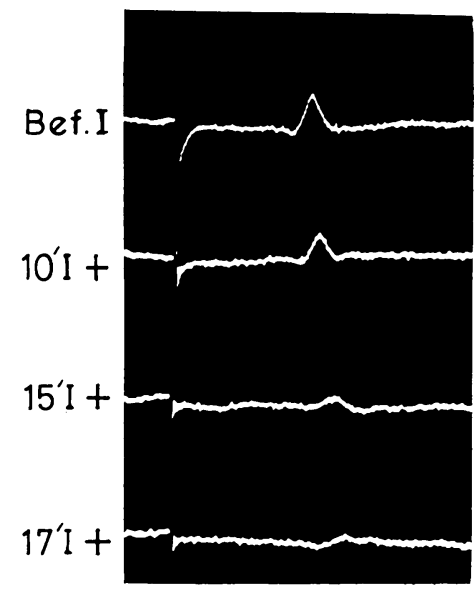

Upper limb arteritis

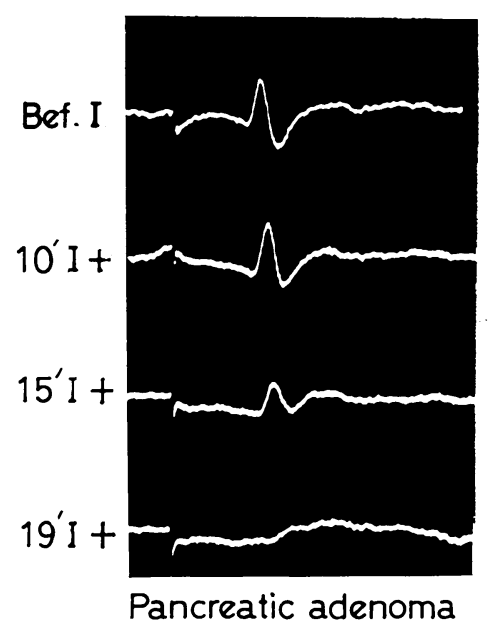

Pancreatic adenoma

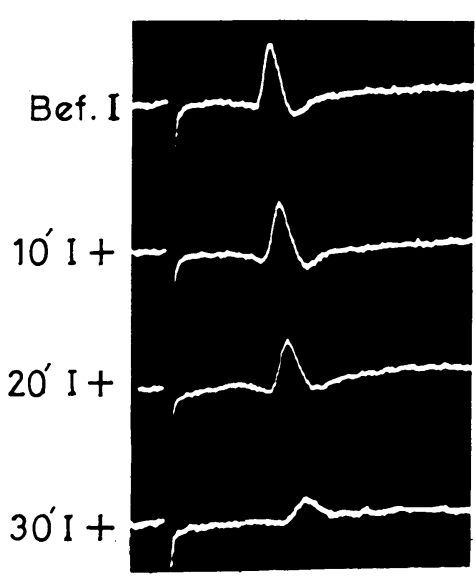

Parathyroid adenoma

$10 \mathrm{msec}$

FIG. 6. Ischaemia test for persistence of NAP in patients with arteritis of upper limbs, pancreatic adenoma, and parathyroid adenoma. 
and all of them showed a normal behaviour during the ischaemic test.

We used the same test in other pathological conditions: one case of upper limb arteritis and one of pancreatic adenoma with hyperinsulinism showed an earlier than normal NAP disappearance, like people undergoing insulin-glucose therapy; and one case of parathyroid adenoma with hypercalcaemia behaved as do diabetic or uraemic patients (Fig. 6). In this, one sees a good example of the biological necessity of homoeostasis: the pathological state lies on both sides of a narrow equilibrium. In this sense 'resistance' to ischaemia does not mean better defence.

In uraemic patients the NAP disappearance time is significantly later than normal, while the rate of increasing latency is equivalent in both. One may wonder whether this is the result of a greater influence of ischaemia upon nerve excitability than on nerve conduction. In this we see a difference between uraemics and diabetics who show a significantly slower rate of increasing latency (Fig. 5) reminiscent of the two kinds of mechanisms in uraemic and diabetic patients (Christensen and Ørskov, 1969).

Interpretation of such results remains difficult. Following Steiness (1963), and Christensen and Orskov (1969), we do not believe they are due to glucose intolerance, as has been proposed for uraemic patients. Christensen and Ørskov have also shown that imbalance in the serum ionic equilibrium, with a consequent change in intracellular ionic equilibrium, does not adequately explain the phenomenon. On the other hand, the enhancement of ischaemic 'resistance' after dialysis excludes the accumulation of nitrogen catabolites as the direct responsible factor. Neither can we believe that the explanation lies in morphological changes of fibres, such as demyelination as suggested by Christensen and Ørskov (1969), or by Gregersen (1968b), since we have seen a rapid return to normal after Rheomacrodex perfusion. Thus, the entire mechanism of action of ischaemia, as well as the altered states of 'resistance' or 'fragility' remain obscure. We do believe however that the socalled 'resistance' to ischaemia in uraemics (as well as diabetics) must be regarded as a pathological fact and not as a favourable defence.

Finally, we suggest that the rapid correction of abnormalities by Rheomacrodex seems to result mainly from a change in the plasma volume, probably without disturbing the plasma extracellular ionic equilibrium which is maintained. Thus the rate and volume of the dialysis seem to have an important role: if too rapid or too great, dialysis could explain the neuropathies which occasionally occur after the beginning of treatment. We therefore recommend more frequent dialysis sessions with a strict dietary regimen in order to avoid large increases in plasma volume requiring more strenuous dialysis.

\section{REFERENCES}

Castaigne, P., Cathala, H.-P., Dry, J., and Mastropaolo, C. (1965). Étude comparée des effets d'une épreuve d'ischémie sur les réponses nerveuses et musculaires chez l'homme normal et le diabétique. Bulletins et Mémoires de la Société Médicale des Hôpitaux de Paris, 116, 1395-1403.

Castaigne, P., Cathala, H.-P., Mastropaolo, C., Dry, J., and Gras, E. (1966a). Les réponses de nerfs et de muscles à des stimulations électriques au cours d'une épreuve de garrot ischémique chez l'homme normal. Revue Fran çaise d'Études Cliniques et Biologiques, 11, 373-387.

Castaigne, P., Cathala, H.-P., Dry, J., and Mastropaolo, C. (1966b). Les réponses des nerfs et des muscles à des stimulations électriques au cours d'une épreuve de garrot ischémique chez l'homme normal et chez le diabétique. Revue Neurologique, 115, 61-66.

Castaigne, P., and Cathala, H.-P. (1967). Une épreuve d'ischémie chez les diabétiques. Journées Annuelles de Diabétologie de l'Hôtel-Dieu, 7, 271-284.

Cathala, H.-P., Beaussart-Boulengé, L., Meyrier, and Damamme, P. (1971). Effets comparés d'une épreuve d'ischémie sur la conduction nerveuse au cours du diabète, après injection massive d'insuline et au cours de l'insuffisance rénale grave. Actualités de Pathologie Musculaire, Marseille. Expansion édit. 577-585.

Cathala, H.-P., and Scherrer, J. (1963). Modifications du potentiel de nerf, sous l'influence d'un brassard ischémiant, chez l'homme. Revue Neurologique, 108, 201-204.

Christensen, N. J., and Ørskov, H. (1969). Vibratory perception during ischaemia in uraemic patients and in subjects with mild carbohydrate intolerance. Journal of Neurology, Neurosurgery, and Psychiatry, 32, 519-524.

Gregersen, G. (1964). Motor-nerve function and duration of diabetics. Lancet, $2,733$.

Gregersen, G. (1968a). Vibratory perception threshold and motor conduction velocity in diabetics and non-diabetics. Acta Medica Scandinavica, 183, 61-65.

Gregersen, G. (1968b). A study of the peripheral nerves in diabetic subjects during ischaemia. Journal of Neurology, Neurosurgery, and Psychiatry, 31, 175-181.

Seneviratne, K. N., and Peiris, O. A. (1970). Peripheral nerve function in chronic liver disease. Journal of Neurology, Neurosurgery, and Psychiatry, 33, 609-614.

Shahani, B., and Russell, W. R. (1969). Motor neurone disease. An abnormality of nerve metabolism. Journal of Neurology, Neurosurgery, and Psychiatry, 32, 1-5.

Steiness, I. (1963). Diabetic neuropathy. Vibration sense and abnormal tendon reflexes in diabetics. Acta Medica Scandinavica, 173, Suppl. 394. 